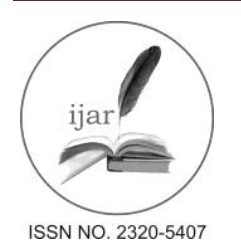

\section{Journal homepage:http://www.journalijar.com Journal DOI:10.21474/IJAR01}

\section{RESEARCH ARTICLE}

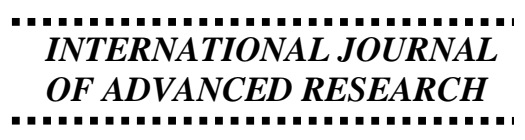

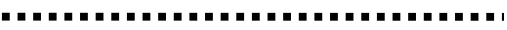

\title{
Reliable Markers of Iron in Chronic Renal Insufficiency - A Study from North Kerala, India.
}

\section{"SindhuPS ${ }^{1}$, Geetha $\mathbf{A}^{2}$ and Sreelatha $\mathbf{M}^{3}$.}

1. Assistant Professor, Department of Biochemistry, Government Medical College, Thrissur,Kerala.

2. Professor, Department of Biochemistry, Government Medical College,Kottayam,Kerala.

3. Professor, Department of Nephrology, Government Medical College, Calicut, Kerala

\section{Manuscript Info}

Manuscript History:

Received: 12 May 2016

Final Accepted: 22 June 2016

Published Online: July 2016

Key words: Chronic kidney disease, iron indices, functional iron deficiency, anemia

*Corresponding Author

SindhuP. S.

\section{Abstract}

Chronic kidney disease is a rapidly increasing condition in India, with majority of the patients diagnosed with anemia. Management of anemia in these patients may remain unsuccessful when the body stores of iron are insufficient. But, assessment and biomarkers of iron status in the CKD patients still remains unresolved. This study aims to assess the iron status and prevalence of functional iron deficiency (FID) in patients in early stages of CKD. A total of 100 CKD patients with stages 3 and 4 were included in the study. Mean $\mathrm{Hb}$ levels ranged from 5.9 to 6.9. A statistically significant positive correlation between $\mathrm{Hb}$ and serum iron $(\mathrm{r}=0.223, \mathrm{p}<0.05)$, serum iron and TSAT $(r=0.634, \mathrm{p}<0.025)$, and serum iron and TIBC $(\mathrm{r}=0.416$, $\mathrm{p}<0.025$ ), was noted. About $29 \%$ of the patients had FID. Serum iron levels were significantly positively correlated with TIBC and TSAT in FID patients $(\mathrm{r}=0.161, \mathrm{p}<0.025 ; \mathrm{r}=0.622, \mathrm{p}<0.025$, respectively). Ferritin and \%TSAT still remain as an achievable and reliable marker for these patients in India, where most of the patients are from a low economic background.

Copy Right, IJAR, 2016, All rights reserved.

\section{Introduction:-}

The incidence of chronic kidney disease (CKD) is rapidly increasing in India.Itis a significant burden to public health, with $17.2 \%$ of the population suffering from different stages of this condition in the country(Singh et al., 2013). Majority of the patients from the rural areas still have limited access to healthcare and often approach hospitals at an advanced stage of kidney disease. Most of the patients with CKD, particularly those with moderately decreased glomerular filtration rate (GFR; $<60 \mathrm{ml} / \mathrm{mt} / 1.73 \mathrm{~m}^{2}$ ) have anaemia (Astor et al., 2002). According to Kidney Disease Improving Global Outcomes (KDIGO), patients with CKD are diagnosed with anemia when the Hb concentration is $<13.0 \mathrm{~g} / \mathrm{dl}$ in males and $<12.0 \mathrm{~g} / \mathrm{dl}$ in females (KDIGO, 2012). In the last two decades, management of anemia in CKD was revolutionized by erythropoiesis-stimulating agents (ESA).

CKD patients tend to have a significant blood loss due to gastrointestinal bleeding, frequent drawing of blood for testing, blood retention in dialyzer tubing, gastrointestinal tubing, folate deficiency, severe hyperparathyroidism, and acute and chronic inflammatory conditions (Fishbane et al., 2004). Thus, patients with anemia require concurrent iron supplementation along with ESA treatment. But, aggressive management of anemia in these patients may remain unsuccessful when the body stores of iron are insufficient.Measure of iron indices are thus imperative to predict the erythropoietic response to iron supplementation and in the decision-making process of anemia therapy in patients with CKD (Kovesdy et al., 2009). ${ }^{5}$ Unfortunately, assessment and biomarkers of iron status in the CKD patients still remains unresolved.

Most of the earlier studies focused on patients with end stage kidney disease on hemodialysis, or on kidney replacement therapy. This study aims toassess the iron status and prevalence of functional iron deficiency (FID) in patients in early stages of CKD $\left(3^{\text {rd }}\right.$ and $4^{\text {th }}$ stage). The study is conducted in a tertiary care hospital andstudy group 
included only $3^{\text {rd }}$ and $4^{\text {th }}$ stage CKD, as $1^{\text {st }}$ and $2^{\text {nd }}$ stages may or may not have undergone treatment in the local health care centers.

\section{Materials and Methods:-}

Study was conducted at Department of Biochemistry in association with the Department of Nephrology, Government Medical College, Calicut. The subjects included all patients with CKD stage 3 and 4 attending Nephrology services in Calicut Medical College during the study period. A total of 100 CKD patients with stages 3 and 4 , defined by creatinine clearance $15-59 \mathrm{ml} / \mathrm{mt}$ by Cockcroft-Gault creatinine clearance formula, and $\mathrm{Hb}$ less than $10 \mathrm{gm} / \mathrm{dl}$, of either sex between ages 10-60 years presenting at Nephrology Department, Calicut Medical College are included in the study. Iron deficiency parameters were defined based on internationally accepted criteria for CKD patients (Wish, 2006).FID is defined as serum ferritin 100-300 $\mu \mathrm{g} / \mathrm{L}$ and TSAT $<20 \%$. The study protocol was approved by the local Ethics Committee. All patients were fully informed about the study and gave their consent.

\section{Results:-}

About $74 \%$ of the patients in the study were in the age group of 30-60 years. All of them were anemic and about $82 \%$ of the participants fall under CKD stage 4 . Most of them (72\%) were involved in strenuous physical activity.

A total of 95 CRI patients had ferritin $>100 \mu \mathrm{g} / \mathrm{l}$ and only $5 \%$ had ferritin $<100 \mu \mathrm{g} / \mathrm{l}$. The mean $\mathrm{Hb}$ levels in the patients belonging to different categories of iron indexes is given in Table 1.

Table 1:- Mean $\mathrm{Hb}$ levels in patients in different categories of iron indexes

\begin{tabular}{|l|l|l|}
\hline S.Ferritin $(\boldsymbol{\mu g} / \mathbf{l})$ & TSAT $(\%)$ & Mean $\mathbf{H b}$ \\
\hline$>100$ & $>20$ & 6.6 \\
\hline$>100$ & $<20$ & 6.5 \\
\hline$<100$ & $<20$ & 6.9 \\
\hline$<100$ & $>20$ & 5.9 \\
\hline
\end{tabular}

There was a statistically significant positive correlation between $\mathrm{Hb}$ and serum iron $(\mathrm{r}=0.223, \mathrm{p}<0.05)$, serum iron and TSAT $(r=0.634, p<0.025)$, serum iron and TIBC $(r=0.416, p<0.025)$ in this study. There was a negative correlation between serum ferritin and TIBC and it was not statistically significant.

FID was present in $29 \%$ of the patients, while $71 \%$ of the patients were without functional deficiency of iron. The hematological and biochemical parameters of the patients with and without FID is given in table 2.

Table 2:- Hematological and biochemical characteristics of patients with and without FID

\begin{tabular}{|l|l|l|}
\hline & $(-$ FID $)$ & $(+$ FID $)$ \\
\hline HB & $6.48 \pm 1.12$ & $6.80 \pm 1.47$ \\
\hline TC & $8824 \pm 2050.07$ & $8672.41 \pm 2285.77$ \\
\hline Crea & $3.50 \pm 0.89$ & $3.21 \pm 1.18$ \\
\hline Cr. Clea & $20.40 \pm 4.78$ & $22.76 \pm 6.52$ \\
\hline S.IRON & $51.15 \pm 41.79$ & $36.73 \pm 12.19$ \\
\hline TIBC & $227.35 \pm 110.16$ & $260.35 \pm 74.71$ \\
\hline TSAT & $23.36 \pm 12.15$ & $14.41 \pm 3.80$ \\
\hline FERRITIN & $488.68 \pm 154.39$ & $201.16 \pm 63.29$ \\
\hline
\end{tabular}

Correlation between the different parameters is given in table 3 . 
Table 3:-Correlation between parameters in patients with and without FID

\begin{tabular}{|c|c|c|c|c|c|}
\hline & & with FI & & without & \\
\hline & Ferritin & -0.532 & $<0.025$ & -0.4 & NS \\
\hline \multirow{3}{*}{$\mathrm{Hb}$} & Serum Iron & 0.367 & $<0.05$ & 0.3 & NS \\
\hline & TIBC & 0.271 & NS & 0.023 & NS \\
\hline & TSAT & 0.187 & $\mathrm{NS}$ & 0.327 & NS \\
\hline \multirow[b]{3}{*}{ S.iron } & TSAT & 0.161 & $<0.025$ & 0.678 & NS \\
\hline & Ferritin & -0.141 & NS & -0.047 & NS \\
\hline & TIBC & 0.622 & $<0.025$ & 0.529 & NS \\
\hline \multirow{3}{*}{ Ferritin } & TSAT & 0.206 & $\mathrm{NS}$ & 0.016 & NS \\
\hline & Urea & 0.475 & $<0.025$ & -0.102 & NS \\
\hline & Creatine & 0.231 & NS & -0.12 & NS \\
\hline & & & & & \\
\hline \multirow{3}{*}{ TIBC } & 1SAT & -0.28 & NS & -0.146 & $<0.5$ \\
\hline & Urea & -0.244 & NS & -0.122 & $<0.5$ \\
\hline & Creatinine & 0.408 & $<0.05$ & 0.013 & NS \\
\hline
\end{tabular}

Serum iron levels were significantly positively correlated with TIBC and TSAT in FID patients $(r=0.161, \mathrm{p}<0.025$; $\mathrm{r}=0.622, \mathrm{p}<0.025$, respectively). There was no significant correlation between these two parameters in patients without FID.

\section{Discussion:-}

Anemia is one of the most common complications in CKD (Patel and Singh, 2010). Insufficient production of erythropoietin, iron deficiency, chronic inflammation, hyperparathyroidism, and blood loss mayall lead to anemia in these patients. It is important to ensure that adequate iron stores are available before erythropoietin therapy is initiated.

To our knowledge, there are only few studies of iron status among CRIsubjects as compared to end-stage renal disease (ESRD) patients. Much has been written on the important contribution of iron deficiency towards anemia and epoetin resistance among ESRD patients. Recent studies, however, show that the chronic renal insufficiency (CRI) population is much larger than the ESRD population and that a substantial number of individuals with CRI are anaemic (Hsu et al.,2002; Kazmi et al., 2001; Nissenson et al., 2001; Hsu et al., 2001).As per the NKF-K/DOQI Practice Guidelines it is important to maintain ferritin levels $\geq 100 \mathrm{ng} / \mathrm{ml}$ and TSAT $\geq 20 \%$ to ensure adequate iron supply for erythropoiesis. The data supporting these targets are also based on studies from ESRD subjects (National Kidney Foundation, 2001). NKF-K/DOQI Practice Guidelines call for more information on Hb levels in patients in the early stages of CKD.Somonitoring and evaluation of the iron status in these subjects are significant. The search for the ideal biomarker that can be considered as a bench mark for iron availability or iron store in the body is ongoing.

Our study included $100 \mathrm{CKD}$ patients with $\mathrm{Hb}$ less than $10 \mathrm{gm} / \mathrm{dl}$ and creatinine clearance between 15$59 \mathrm{ml} / \mathrm{mt}$.Ninety five percent of anemic CKDsubjects had ferritin $>100 \mu \mathrm{g} / \mathrm{l}$ and only $5 \%$ had ferritin $<100 \mu \mathrm{g} / \mathrm{l}$. One half of anemic CKDsubjects had TSAT $>20 \%$ and $50 \%$ had TSAT $<20 \%$. In this study, the general view of anemia among the patients with CKD is that of FID. This is characterized by high serum ferritin levels $(>100 \mu \mathrm{g} / \mathrm{dL}$ and $<300 \mu \mathrm{g}$ ). FID may be caused by impaired iron mobilization or due to overutilization of iron. Of the total 100 subjects, $3 \%$ had ferritin levels more than $500 \mathrm{ng} / \mathrm{mL}$ and do not require iron supplementation as per guidelines (KDOQI, 2006). Earlier studies had shown that in dialysis patients, elevated ferritin levels were associated with FID, and the iron status improved with iron supplementation (Kopelman et al., 2007). The average serum iron levels in the two groups of patients, with and without FID, was in the range of 37.13-51.15. TIBC and \%TSAT lacked a significant correlation, probably due to inflammation and malnutrition in patients with CKD.

Among the different biomarkers of iron status, serum ferritin was considered as a reliable index of iron stores in the bone marrow (Rocha et al.,2009). Based on its extensive use, familiarity, and availability of literature base, serum ferritin and TSAT were used as two reliable indices foriron status assessment.But, values of these two indices were found to diverge and this incongruity raised the need to seek alternative iron markers to predict the response to iron 
therapy (Rafi et al.,2007; Chinnapu Reddy et al., 2013). One such marker, the soluble or serum transferrin receptor (sTfR) represents the total transferrin receptors present in the body and has increased presentation in the setting of iron deficiency. It was earlier considered as an indicator of functional iron status, but was not more advantageous than the conventional laboratory indicators, and did not correlate with inflammatory parameters (Wians et al., 2001; Łukaszyk et al., 2015). It was thought to be a more reliable test than serum ferritin, but Fernandez-Rodriguez et al. found sTfR to be less accurate than serum ferritin (Fernandez-Rodriguez et al., 1999). Moreover, sTfr assay is relatively expensive and is not widely available in India. In patients with chronic renal failure and stable kidney disease not receiving iron or ESAs, the sTfr concentration alone proved inferior to that of serum ferritin in detecting those with coexisting iron deficiency (Fernandez-Rodriguez et al., 1999).

The reticulocyte $\mathrm{Hb}$ content $(\mathrm{CHr})$, the measure of the amount of $\mathrm{Hb}$ in the reticulocytes, is a reasonably good indicator of iron stores available for incorporation into new red blood cells. CHrwhen studied as anindexof iron store, revealed to be more accurate and reproducible, but the optimal cutoff value could not be decided (Fishbane et al., 2001). Hematology analyzers to check this index is still not widely available in conventional laboratories in the country. .

Another alternative iron marker is the percentage of hypochromic red blood cells (PHRC), a test of the concentration of $\mathrm{Hb}$ in $\mathrm{RBC}$. PHRC was comparable to $\mathrm{CHr}$ in terms of its utility, but the storage issue will remain a limiting factor as storage of full blood count samples leads to erroneous increase in PHRC. PHRC and CHr have limitations in terms of sample stability and availability of analyzing equipment.Bone marrow examination, for the sole purpose of assessing iron stores is also not justifiable.

Discovery of hepcidin-25 showed that iron status in CRI patients isassociated with inflammation and reduced clearance of hepcidin in CKD.In one of the studies, hepcidin was a relatively good predictor of FID in patients undergoing hemodialysis (Malyszko et al., 2012). But this should be taken with caution as intra-individual variability in hepcidin has been reported (Peters et al., 2012). In another study, no correlation was found between hepcidin and ferritin in patients with FID (Lukaszyk et al., 2015). Hepcidin level in CKD patients may not be of greater diagnostic value than the ferritin level,but further studies are required (Peters et al., 2012). The utility of hepcidin measurement as a diagnostic tool is currently uncertain and for the time being this technique remains a research investigation.More studies are required in CKD patients to confirm the use of this index. Other novel biomarkers like GDF-15, hemojuvelin, and zonulin are also being studied as indices for iron status in these patients (Peters et al., 2012; Malyszko et al., 2012: World Health Organization, 1968; Malyszko et al., 2013).

With lack of consensus and confirmatory evidence about many markers, the debate over which is the most appropriate marker is still ongoing. Our knowledge regarding the utility and reliability of many of the markers are still immature and inadequate. More robust evidence, based on larger studies on CKD subjects, is needed for these biomarkers to be widely used.Until new parameters are explored and recommended, serum ferritin and TSAT can still guide the decision.

Further, for most of the novel biomarkers better standards of handling and specimen storage are needed. Lack of standardized analyzers, and high cost of testing reduce the accessibility of these tests, particularly for patients from a lower socioeconomic background.CKD is a global threat to public health in general population especially in a developing country like India,as therapy is expensive andlifelong.About $72 \%$ of the patients in this study belonged to the lower strata of economic status.Given the enormous cost and time to be spent towards the number of tests, ferritin and \%TSAT still remain as an achievable and reliable marker for these patients in India.

\section{Conclusions:-}

There is lack of consensus and confirmatory evidence on the most appropriate iron index for CKD. This study shows that, in a country like India, serum ferritin and \% TSAT can guide the decision on treatment of anemia in patients with chronic renal insufficiency. 


\section{References:-}

1. Astor,BC.,Muntner, P., Levin, A., Eustace, JA., and Coresh, J.(2002). Association of kidney function with anaemia :The Third National Health and Nutrition Examination Survey(1988-1994).Arch Intern Med.,162: 1401 - 1408.

2. Chinnapu Reddy, G., Devaki, R., andPragna Rao: (2013). Iron indices in patients with functional anemia in CKD. JIntFedClinChem., 24: 3-4.

3. Fernandez-Rodriguez, AM., Guindeo-Casasus,MC.,Molero-Labarta, T., Dominguez-Cabrera, C., Hortal-Casc n L., Perez-Borges, P., Vega-Diaz, N., Saavedra-Santana, P., and Palop-Cubillo, L: (1999). Diagnosis of iron deficiency in chronic renal failure. Am J Kidney Dis., 34:508- 513.

4. Fishbane, S., Kalantar-Zadeh, K., and Nissenson, AR: (2004). Serum ferritin in CKD: Reconsidering the upper limit for iron treatment. SeminDial, 17:336-341.

5. Fishbane, S., Shapiro, W., Dutka, P., Valenzuela,OF.,andFaubert, J: (2001). A randomized trial of iron deficiency testing strategies in hemodialysis patients. Kidney Int., 60:2406- 2411.

6. Hsu,CY., Bates, DW., Kuperman, GJ., and Curhan, GC: (2001). Relationship between hematocrit and renal function in men and women. Kidney Int., 59: 725-731.

7. Hsu,CY., McCulloch, CE., and Curhan, GC: (2002). Epidemiology of anemia associated with chronic renal insufficiency among adults in the Unites States: Results from NHANES III. J Am SocNephrol, 13: 504-510.

8. Kazmi, WH., Kausz, AT., Khan, S., Abichandani, R., Ruthazer, R., Obrador, GT., and Pereira, BJG: (2001). Anemia: An early complication of chronic renal insufficiency. Am J Kidney Dis., 38: 803-812.

9. KDIGO. (2012). KDIGO Clinical Practice Guideline for Anemia in CKD. Kidney Int Suppl., 2:4.

10. KDOQI: (2006). Clinical Practice Guidelines and Clinical Practice Recommendations for Anemia in CKD. Am J Kidney Dis.,47:(5 Suppl 3):S11-145.

11. Kopelman,RC., Smith, L., Peoples, L., Biesecker, R., and Rizkala, AR: (2007). Functional iron deficiency in hemodialysis patients with high ferritin. HemodialInt, 11(2):238-246.

12. Kovesdy, CP., Estrada, W., Ahmadzadeh, S., and Kalantar-Zadeh, K: (2009). Association of markers of iron stores with outcomes in patients with non-dialysisdependent CKD. Clin J Am SocNephrol., 4(2):435-441.

13. Łukaszyk, E.,Łukaszyk, M.,Koc-Żórawska, E.,Tobolczyk, J.,Bodzenta-Łukaszyk, A.,andMałyszko, J: (2015). Iron Status and Inflammation in Early Stages of CKD.Kidney Blood Press Res., 40:366-373.

14. Malyszko, J., Koc-Żórawska, E., Levin-Iaina, N., Małyszko, J., Koźmiński, P., Kobus, G., Myśliwiec, M: (2012). New parameters in iron metabolism and functional iron deficiency in patients on maintenance hemodialysis. Pol Arch Med Wewn, 122:537-542.

15. Malyszko, J., Koc-Zorawska, E., Malyszko,JS.,Glowinska, I., Mysliwiec, M., andMacdougall, IC: (2013). GDF15 is related to anemia and hepcidin in kidney allograft recipients. Nephron ClinPract, 123:112-117. .

16. National Kidney Foundation: (2001). NKF-K/DOQI Clinical Practice Guidelines for Anemia of CKD: Update 2000. Am J Kidney Dis., 37 [suppl1]: S182-S238.

17. Nissenson, AR., Collins,AJ., Hurley, J., Petersen, H., Pereira, BJG., and Steinberg, EP: (2001). Opportunities for improving the care of patients with chronic renal insufficiency: Current practice patterns. J Am SocNephrol., 12: 1713-20.

18. Patel,TV.,and Singh, AK: (2010). Anemia in CKD: new advances. Heart Fail Clin.,6(3):347-357.

19. Peters, HP., Rumjon, A., Bansal, SS., Laarakkers, CM., van den Brand, JA., Sarafidis, P., Musto, R., Malyszko, J., Swinkels, DW., Wetzels,JF., andMacdougall, IC: (2012). Intra-individual variability of se- rum hepcidin-25 in haemodialysis patients using mass spectrometry and ELISA. Nephrol Dial Transplant., 27: 3923-3929.

20. Rafi, A., Karkar, A., and Abdelrahman, M:(2007). Monitoring Iron status in End-Stage Renal Disease Patients on Hemodialysis. Saudi J Kidney Dis Transpl.,18:73-78.

21. Rocha, LA., Barreto, DV., Barreto, FC., Dias, CB., Moysés, R., Silva, MR., Moura, LA., Draibe, SA., Jorgetti, V., Carvalho, AB., and Canziani ME.:(2009). Serum ferritin level remains a reliable marker of bone marrow iron stores evaluated by histomorphome- try in hemodialysis patients. Clin J Am SocNephrol., 4: 105-109.

22. Singh, AK., Farag, Youssef MK., Mittal BV., Subramanian, K., KeithiReddy,S., Acharya, VN., Almeida, AF., Channakeshavamurthy, A.,Ballal,HS., Gaccione, Issacs, R., Jasuja,S., Kirpalani, AL., Vijay,Kher., Modi, GK., Nainan, G., Jai Prakash., Rana, DS., Sreedhara, R., Sinha, DK., Shah, Bharat., Sham Sunder., Sharma, RK., Seetharam, S., Raju, TR andRajapurkar, M.(2013). Epidemiology and risk factors of CKD in India - results from the SEEK (Screening and Early Evaluation of Kidney Disease) study. BMC Nephrol., 14:114.

23. Wians, FH Jr., Urban JE, Keffer,JH., and Kroft, SH : (2001). Discriminating between iron deficiency anemia and anemia of chronic disease using traditional in- dices of iron status vs transferrin receptor concentration. Am $\mathrm{J}$ ClinPathol., 115: 112-118.

24. Wish, JB: (2006). Assessing iron status: Beyond serum ferritin and transferrin saturation. Clin J Am SocNephrol., 1:S4-S8.

25. World Health Organization: (1968). Nutritional anemias: Report of a WHO Scientific Group. World Health Organ Tech Rep Ser., 405:5-37. 